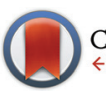

CrossMark \& click for updates

Cite this: Polym. Chem., 2015, 6 , 5653

Received 16th January 2015,

Accepted 16th February 2015

DOI: $10.1039 / c 5 p y 00065 c$

www.rsc.org/polymers

\title{
A convenient synthesis strategy for microphase- separating functional copolymers: the cyclohydrocarbosilane tool box $\dagger$
}

\begin{abstract}
V. Rittscher and M. Gallei*
A novel and feasible strategy for the preparation of functional polyhydrocarbosilane-based homo and block copolymers is described via a combination of anionic ring-opening polymerization of methylsilacyclobutane (MSB) and styrene followed by postmodification applying hydrosilylation protocols. Sterically demanding and functional vinyl compounds such as $N$-vinylcarbazole (NVC), vinylferrocene (VFc), and 9,10-di(1-naphthalenyl)-2-vinylanthracene (VADN) are block-selectively incorporated into the PMSB backbone with adjustable functional group contents between 26 mol\% to 43 mol\% with respect to the $\mathrm{Si}-\mathrm{H}$ functionalities for the PMSB homopolymers and contents ranging from 28 mol\% to $63 \mathrm{~mol} \%$ for the corresponding diblock copolymers as evidenced by ${ }^{1} \mathrm{H}$ NMR spectroscopy. The novel functional diblock copolymers are capable of undergoing microphase separation as shown via TEM.
\end{abstract}

\section{Introduction}

Block copolymers which consist of two or more polymer segments covalently connected to each other have attracted enormous attention in the recent past due to their unique capability of undergoing microphase separation in the bulk or self-organization in (selective) solvents. ${ }^{1-6}$ As a result, various structures such as spheres, cylinders, lamellae and co-continuous structures as well as nanoscale porous structures can be obtained. ${ }^{7,8}$ Therefore, applications of block copolymers are manifold ranging, e.g. from fields of nanolithography, drug delivery to separation technologies. ${ }^{4}$ Furthermore, block copolymers and architectures thereof can consist of so-called stimuli-responsive polymers i.e., polymers which are capable of changing their conformation, solubility, or even break or form covalent bonds caused by different external triggers such as the change of temperature, $\mathrm{pH}$ value, light, redox reagents or electrical field. ${ }^{9-19}$ As another important and feasible route towards functional materials, block copolymer self-assembly strategies can be advantageously used for the controlled buildup of ceramic nanostructures obtained by pyrolysis of inorganic/organic block copolymers. There, the inorganic block

Ernst-Berl-Institut für Technische und Makromolekulare Chemie, Technische Universität Darmstadt, Alarich-Weiss-Str. 4, D-64287 Darmstadt, Germany. E-mail:m.gallei@mc.tu-darmstadt.de

$\dagger$ Electronic supplementary information (ESI) available: Additional data on PMSB homopolymers, ${ }^{1} \mathrm{H}$ NMR spectra, SEC, and DSC of all functional hydrosilylated PMSB homo- and block copolymers, ${ }^{1} \mathrm{H}$ NMR spectrum of NVC@PS- $b$ PMSB1 precipitated in methanol, cyclic voltammogram of VFc@PMSB1, TGA of VFc@PMSB1, and XRD pattern of ceramized VFc@PMSB. See DOI: 10.1039/ c5py00065c segment - also referred to as preceramic block segment - is directly converted into the ceramic material after thermal treatment maintaining the block copolymer-templated nanostructure. ${ }^{20,21}$ Different approaches for the preparation of ceramic materials inclusively nanocomposites are known and excellent reviews within that field are given for example by Orilall and Wiesner ${ }^{22}$ and other authors. ${ }^{23-29}$

All these above mentioned powerful applications based on block copolymers necessitates the precise synthesis of the underlying block copolymer architectures comprising adjustable block length and exact (block) polymer constitution. For this purpose, especially controlled or living polymerization protocols are applied. ${ }^{30-34}$ Although there is tremendous effort in terms of functional block copolymer synthesis in the last decades, there are still challenges to overcome in the field of living and controlled polymerization strategies for some functional monomers. Therefore, protocols for postmodification of homopolymers and block copolymers have been applied for many years in order to improve properties and to introduce certain functionalities. Powerful polymer postmodification methods for introducing pendant non-functional side groups or responsive moieties with additional functionalities into silane-, siloxane- and carbosilane-based polymers usually focus on hydrosilylation, hydroboration, and thiol-ene chemistry. ${ }^{35-43}$ There, especially the group of Frey succeeded in the formation of various functional polycarbosilanebased architectures by using convenient hydrosilylation protocols. ${ }^{44-47}$ Especially polycarbosilanes gained significant attention due to their outstanding potential to be converted into oxygen-free ceramic materials. ${ }^{48-50}$ More basic requirements for well-defined microphase separation of block copoly- 
mers are e.g., precise control over blocking efficiency and narrowly distributed polymer masses. In order to achieve these demands, especially anionic ring-opening polymerization routes starting from ring-strained cyclic carbosilane monomers has been studied by some groups. ${ }^{51-60}$ For example, Kim et al. reported the block copolymerization of 1,1-dimethylsilacyclobutane (DMSB) with polystyrene. ${ }^{61}$ The authors succeeded in preparing microphase-separated block copolymer structures which were converted into highly-ordered silicon-carbide ceramics after thermal treatment. As another example, polycarbosilane-based block copolymer micelles have been synthesized and converted into spherical SiC ceramics by pyrolysis. ${ }^{62}$

In this contribution polyhydrocarbosilane-containing block copolymers with polystyrene (PS) as second block segment are prepared by using sequential anionic polymerization protocols. For this purpose, the anionic ring-opening polymerization (ROP) of methylsilacyclobutane (MSB) is investigated in order to obtain hydrocarbosilane moieties capable of undergoing efficient subsequent hydrosilylation reaction. Moreover, block copolymers are prepared featuring reactive $\mathrm{Si}-\mathrm{H}$ moieties in the polycarbosilane segment which are successfully postmodified with three different functional vinyl compounds i.e., $N$-vinylcarbazole (NVC), vinylferrocene (VFc) and 9,10-di(1-naphthalenyl)-2-vinylanthracene (VADN) (Fig. 1).

Although block copolymer formation of PNVC and PVFc were described in literature by applying controlled and living polymerization protocols, preparation of polymers with high molar masses, narrow molecular weight distribution, welldefined constitutions without the presence of side-products and significant yields are still challenging. ${ }^{58,63-66}$ Within the present work we show how these challenging vinyl compounds i.e., NVC, VFc, and VADN can be successfully incorporated into polyhydrocarbosilanes and corresponding block copolymers with polystyrene (PS). The novel functional polymers and block copolymers are investigated with respect to their molar masses, constitution, and thermal behaviour. Finally, polyhydrocarbosilane-containing block copolymers with functional moieties are shown to undergo microphase-separation. In the case of PMSB with pendant VFc groups it is shown that pyrolysis yields oxygen-free $\mathrm{SiC} / \mathrm{Fe}$-containing ceramic materials. We expect this postmodification route of polyhydrocarbosilanebased block copolymers by using hydrosilylation protocols as

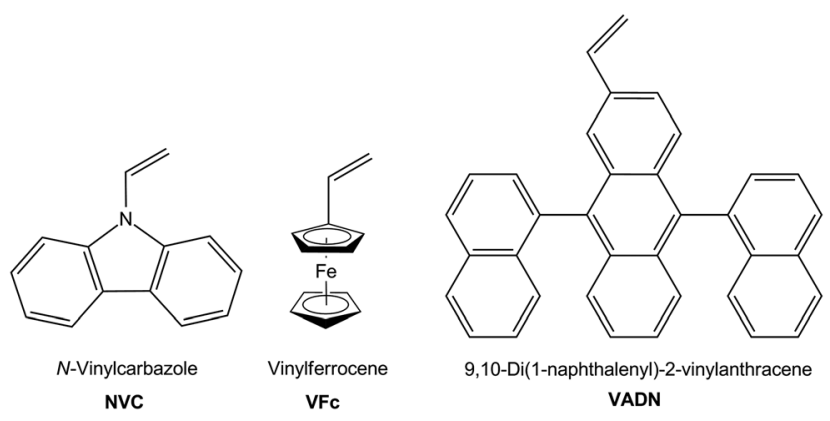

Fig. 1 Vinyl compounds for intended postmodification of polyhydrocarbosilane-containing homo- and diblock copolymers. universal methodology for the controlled buildup of functional block copolymers which will be useful for a manifold of applications in the field of nanotechnology.

\section{Experimental}

\subsection{Materials and methods}

All solvents and reagents were purchased from Alfa Aesar, Sigma Aldrich, Fisher Scientific, ABCR and Merck and used as received unless otherwise stated. Platinum(0)-1,3-divinyl1,1,3,3-tetramethyldisiloxane complex in xylene $(2.1-2.4 \% \mathrm{Pt})$ and $N$-vinylcarbazole (NVC) were used as received. 1-Methylsilacyclobutane (MSB) and styrene were stirred over calcium hydride $\left(\mathrm{CaH}_{2}\right)$, distilled and stored in a glove-box at $-16{ }^{\circ} \mathrm{C}$. $\mathrm{MSB}^{58}$ and $\mathrm{VADN}^{67}$ were synthesized as described elsewhere. Tetrahydrofuran (THF) and toluene were distilled from sodium/benzophenone under reduced pressure (cryo-transfer) prior to the addition of 1,1-diphenylethylene and $n$-butyllithium $(n-\mathrm{BuLi})$ followed by a second cryo-transfer. Methylene chloride, diethylether, and ethanol were stirred over molecular sieves overnight, and degassed before use. Vinylferrocene (VFc) was synthesized and purified described elsewhere. ${ }^{66}$ Deuterated solvents were purchased from Deutero $\mathrm{GmbH}$, Kastellaun, Germany. All syntheses were carried out under an atmosphere of nitrogen using Schlenk techniques or a glovebox equipped with a Coldwell apparatus.

\subsection{Preparation of PMSB}

Exemplary synthesis of PMSB with a molar mass of approx.

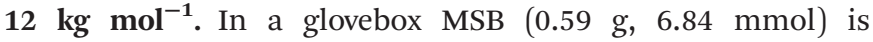
dissolved in neat THF (15 mL) in an ampoule equipped with stirring bar. The solution is cooled to $-78{ }^{\circ} \mathrm{C}$ by using the Coldwell apparatus and the polymerization is initiated by adding $31 \mu \mathrm{L} \mathrm{n}$-BuLi (1.6 $\mathrm{M}$ in hexane). After $1 \mathrm{~h}$ the reaction is terminated by adding methanol and the solution poured into 10 -fold excess of methanol. PMSB precipitates as a colourless liquid (yield: $0.51 \mathrm{~g}, 87 \%) .{ }^{58}$

${ }^{1} \mathrm{H}-\mathrm{NMR}\left(\mathrm{CDCl}_{3}, 300 \mathrm{MHz}, 300 \mathrm{~K}\right): \delta=3.827-3.716(\mathrm{~m}$, $\mathrm{Si}-\mathrm{H}), 1.514-1.360\left(\mathrm{~m}, 3-\mathrm{H}_{2}\right), 0.775-0.556\left(\mathrm{~m}, 2-\mathrm{H}_{4}\right), 0.041$ (d, $\left.1-\mathrm{H}_{3}\right)$ ppm. $J_{1-\mathrm{H}, \mathrm{Si}-\mathrm{H}}=3.57 \mathrm{~Hz}$.

${ }^{13} \mathrm{C}-\mathrm{NMR}\left(\mathrm{CDCl}_{3}, 75 \mathrm{MHz}, 300 \mathrm{~K}\right): \delta=19.923$ (3-C), 17.067 (2-C), -6.058 (1-C) ppm.

\subsection{Preparation of polystyrene-block-polymethylsilacyclo- butane}

Exemplary synthesis of PS- $\boldsymbol{b}$-PMSB1. In a glovebox styrene $(1.05 \mathrm{~g}, 10.08 \mathrm{mmol})$ is dissolved in neat toluene $(20 \mathrm{~mL})$ in an ampoule equipped with stirring bar followed by the addition of sec-BuLi (38 $\mu \mathrm{L}, 1.3 \mathrm{M}$ in hexane) using a syringe. After $1 \mathrm{~h}$ of stirring at room temperature the mixture is cooled to $-78{ }^{\circ} \mathrm{C}$ by using the Coldwell apparatus and precooled THF $(20 \mathrm{~mL})$ is added. After stirring the solution for $30 \mathrm{~min}$ at $-78{ }^{\circ} \mathrm{C}$, precooled MSB $(0.45 \mathrm{~g}, 5.22 \mathrm{mmol})$ is added by using a syringe. Stirring is continued for $1 \mathrm{~h}$ at $-78^{\circ} \mathrm{C}$. The reaction is terminated by adding methanol and the whole reaction 
mixture is poured into 10 -fold excess of methanol. The polymer precipitates as a colourless solid, filtered and dried in vacuo (yield: $1.28 \mathrm{~g}, 84 \%$ ).

${ }^{1} \mathrm{H}-\mathrm{NMR}\left(\mathrm{CD}_{2} \mathrm{Cl}_{2}, 300 \mathrm{MHz}, 300 \mathrm{~K}\right): \delta=7.382-6.886(\mathrm{~m}$, 5- $\left.\mathrm{H}_{2}, 6-\mathrm{H}_{1}\right), 6.880-6.295\left(\mathrm{~m}, 4-\mathrm{H}_{2}\right), 3.931-3.628(\mathrm{~m}, \mathrm{Si}-\mathrm{H})$, 2.378-1.168 (m, 1- $\mathrm{H}_{2}, 2-\mathrm{H}_{1}, 9-\mathrm{H}_{2}$ ), 0.894-0.461 (m, 8- $\left.\mathrm{H}_{4}\right), 0.049$ $\left(\mathrm{d}, 7-\mathrm{H}_{3}\right) \mathrm{ppm} . J_{7-\mathrm{H}, \mathrm{Si}-\mathrm{H}}=3.68 \mathrm{~Hz}$.

${ }^{13} \mathrm{C}-\mathrm{NMR}\left(\mathrm{CD}_{2} \mathrm{Cl}_{2}, 75 \mathrm{MHz}, 300 \mathrm{~K}\right): \delta=145.809$ (3-C); 128.425, 128.035, 126.073 (4-C, 5-C, 6-C); 41.015 (2-C); 40.766 (1-C); 20.160 (9-C), 17.274 (8-C), -6.091 (7-C) ppm.

\subsection{Hydrosilylation of PMSB with functional vinyl compounds}

Exemplary hydrosilylation of PMSB with VFc/NVC. In a $50 \mathrm{~mL}$ schlenk-flask equipped with stirring bar toluene (15 mL), $0.1 \mathrm{~g}$ PMSB homopolymer (containing $1.16 \mathrm{mmol}$ of Si-H units) and platinum(0)-1,3-divinyl-1,1,3,3-tetramethyldisiloxane complex solution $\left(11 \mu \mathrm{L}, 2 \times 10^{-4} \mathrm{~mol} \mathrm{Pt} \mathrm{mol}^{-1}\right.$ with respect to the $\mathrm{Si}-\mathrm{H}$ units) are added. After stirring the mixture for $15 \mathrm{~min}$ at room temperature $\operatorname{NVC}(0.22 \mathrm{~g}, 1.16 \mathrm{mmol})$ or VFc $(0.25 \mathrm{~g}, 1.16 \mathrm{mmol})$ is added and stirring is continued for $24 \mathrm{~h}$ at room temperature. The temperature is increased to $50{ }^{\circ} \mathrm{C}$ and stirring is continued for another $96 \mathrm{~h}$. After that time the solution is poured into a 10 -fold excess of methanol for polymer precipitation yielding NVC@PMSB (0.21 g, 50\%) as colourless liquid or VFc@PMSB (0.31 g, 84\%) as a brownish liquid after filtration and drying in vacuo. In the case of VADN@PMSB, $0.05 \mathrm{~g}$ PMSB (0.58 mmol Si-H units), $5.5 \mu \mathrm{L}$ Karstedt's complex solution, and VADN ( $0.27 \mathrm{~g}, 0.58 \mathrm{mmol})$ are used applying exactly the same protocol yielding $0.16 \mathrm{~g}$ (41\%) product as yellow solid.

NVC@PMSB: ${ }^{1} \mathrm{H}-\mathrm{NMR}\left(\mathrm{CDCl}_{3}, 300 \mathrm{MHz}, 300 \mathrm{~K}\right): \delta=$ 8.22-7.89 (m, 15- $\left.\mathrm{H}_{2}\right), 7.54-7.05\left(\mathrm{~m}, 12-\mathrm{H}_{2}, 13-\mathrm{H}_{2}, 14-\mathrm{H}_{2}\right)$, 4.43-4.10 (m, 10- $\mathrm{H}_{2}$ ), 3.91-3.70 (m, Si-H), 1.63-1.20 (m, 3- $\mathrm{H}_{2}$, 7- $\left.\mathrm{H}_{2}\right), 1.20-0.99\left(\mathrm{~m}, 9-\mathrm{H}_{2}\right), 0.79-0.42\left(\mathrm{~m}, 2-\mathrm{H}_{2}, 4-\mathrm{H}_{2}, 6-\mathrm{H}_{2}\right.$, 8- $\left.\mathrm{H}_{2}\right), 0.19-(-0.10)\left(\mathrm{m}, 1-\mathrm{H}_{3}, 5-\mathrm{H}_{3}\right) \mathrm{ppm}$.

VFc@PMSB: ${ }^{1} \mathrm{H}-\mathrm{NMR}\left(\mathrm{CDCl}_{3}, 300 \mathrm{MHz}, 300 \mathrm{~K}\right): \delta=$ 4.28-4.00 (m, 14- $\left.\mathrm{H}_{5}, 13-\mathrm{H}_{2}, 12-\mathrm{H}_{2}\right), 2.47-2.27\left(\mathrm{~m}, 10-\mathrm{H}_{2}\right)$, 3.90-3.76 (m, Si-H), 1.68-1.19 (m, 3- $\left.\mathrm{H}_{2}, 7-\mathrm{H}_{2}\right), 0.96-0.46$ (m, $\left.2-\mathrm{H}_{2}, 4-\mathrm{H}_{2}, 6-\mathrm{H}_{2}, 8-\mathrm{H}_{2}, 9-\mathrm{H}_{2}\right), 0.22-(-0.14)\left(\mathrm{m}, 1-\mathrm{H}_{3}, 5-\mathrm{H}_{3}\right)$ ppm.

VADN@PMSB: ${ }^{1} \mathrm{H}-\mathrm{NMR}\left(\mathrm{CD}_{2} \mathrm{Cl}_{2}, 300 \mathrm{MHz}, 300 \mathrm{~K}\right): \delta=$ 8.21-6.78 (m, 12- $\mathrm{H}_{1}, 13-\mathrm{H}_{1}, 17-\mathrm{H}_{1}, 18-\mathrm{H}_{1}, 19-\mathrm{H}_{1}, 20-\mathrm{H}_{1}, 24-\mathrm{H}_{1}$, $26-\mathrm{H}_{2}, 27-\mathrm{H}_{2}, 28-\mathrm{H}_{2}, 30-\mathrm{H}_{2}, 31-\mathrm{H}_{2}, 32-\mathrm{H}_{2}, 33-\mathrm{H}_{2}$ ), 3.81-3.46 (m, $\left.\mathrm{Si}-\mathrm{H}, 10-\mathrm{H}_{2}\right), 2.56-(-0.62)\left(\mathrm{m}, 1-\mathrm{H}_{3}, 2-\mathrm{H}_{2}, 3-\mathrm{H}_{2}, 4-\mathrm{H}_{2}, 5-\mathrm{H}_{3}\right.$, $\left.6-\mathrm{H}_{2}, 7-\mathrm{H}_{2}, 8-\mathrm{H}_{2}, 9-\mathrm{H}_{2}\right)$ ppm.

\subsection{Hydrosilylation of PS- $b$-PMSB with NVC}

Exemplary hydrosilylation of PS- $b$-PMSB3 with NVC. In a $50 \mathrm{~mL}$ schlenk-flask equipped with stirring bar toluene (30 mL), PS- $b$-PMSB3 (0.3 g, with $1.35 \mathrm{mmol}$ of Si-H units) and platinum(0)-1,3-divinyl-1,1,3,3-tetramethyldisiloxane complex solution $\left(13 \mu \mathrm{L}, 2 \times 10^{-4} \mathrm{~mol} \mathrm{Pt} \mathrm{mol}^{-1}\right.$ with respect to the $\mathrm{Si}-\mathrm{H}$ units) are added. After stirring the mixture for $15 \mathrm{~min}$ at room temperature NVC $(0.26 \mathrm{~g}, 1.35 \mathrm{mmol})$ is added and stirring is continued for $120 \mathrm{~h}$ at room temperature. The solution is poured into a 10-fold excess of methanol for polymer precipitation yielding NVC@PS- $b$-PMSB (0.40 g, 41\%) as white solid after filtration and drying in vacuo.

${ }^{1} \mathrm{H}-\mathrm{NMR}\left(\mathrm{CD}_{2} \mathrm{Cl}_{2}, 500 \mathrm{MHz}, 300 \mathrm{~K}\right): \delta=8.18-7.95(\mathrm{~m}$, 21- $\mathrm{H}_{2}$ ), 7.54-6.29 (m, 4- $\mathrm{H}_{2}, 5-\mathrm{H}_{2}, 6-\mathrm{H}_{1}, 18-\mathrm{H}_{2}, 19-\mathrm{H}_{2}, 20-\mathrm{H}_{2}$,), 4.46-4.14 (m, 16- $\mathrm{H}_{2}$ ), 3.92-3.66 (m, Si-H), 2.33-1.25 (m, 1- $\mathrm{H}_{2}$, $\left.2-\mathrm{H}_{1}, 9-\mathrm{H}_{2}, 13-\mathrm{H}_{2}\right)$, $1.22-0.99\left(15-\mathrm{H}_{2}\right), 0.83-0.45\left(\mathrm{~m}, 8-\mathrm{H}_{2}\right.$, $\left.10-\mathrm{H}_{2}, 12-\mathrm{H}_{2}, 14-\mathrm{H}_{2}\right), 0.23-(-0.13)\left(\mathrm{m}, 7-\mathrm{H}_{3}, 11-\mathrm{H}_{3}\right) \mathrm{ppm}$.

\subsection{Hydrosilylation of PS- $b$-PMSB with VFc}

Exemplary hydrosilylation of PS- $b$-PMSB3 with VFc. In a $50 \mathrm{~mL}$ schlenk-flask equipped with stirring bar toluene (30 mL), PS- $b$-PMSB3 (0.2 g, with $0.90 \mathrm{mmol}$ of Si-H units) and platinum(0)-1,3-divinyl-1,1,3,3-tetramethyldisiloxane complex

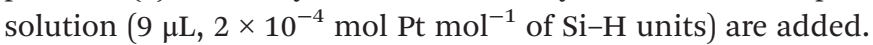
After stirring the mixture for $15 \mathrm{~min}$ at room temperature VFc $(0.19 \mathrm{~g}, 0.90 \mathrm{mmol})$ is added and stirring is continued for $120 \mathrm{~h}$ at room temperature. The solution is poured into a 10-fold excess of methanol for precipitation of VFc@PS- $b$ PMSB3 (yield: $0.30 \mathrm{~g}, 54 \%$ ) as orange solid after filtration and drying in vacuo.

${ }^{1} \mathrm{H}-\mathrm{NMR}\left(\mathrm{CD}_{2} \mathrm{Cl}_{2}, 500 \mathrm{MHz}, 300 \mathrm{~K}\right): \delta=7.39-6.30\left(\mathrm{~m}, 4-\mathrm{H}_{2}\right.$, 5- $\mathrm{H}_{2}, 6-\mathrm{H} 1$ ), 4.28-3.87 (m, 18- $\mathrm{H}_{2}, 19-\mathrm{H}_{2}, 20-\mathrm{H}_{5}$ ), 3.87-3.69 (m, $\mathrm{Si}-\mathrm{H}), 2.48-1.45\left(\mathrm{~m}, 1-\mathrm{H}_{2}, 2-\mathrm{H}_{1}, 9-\mathrm{H}_{2}, 13-\mathrm{H}_{1}, 16-\mathrm{H}_{2}\right), 1.00-0.37$ $\left(\mathrm{m}, 8-\mathrm{H}_{2}, 10-\mathrm{H}_{2}, 12-\mathrm{H}_{2}, 14-\mathrm{H}_{2}, 15-\mathrm{H}_{2}\right), 0.22-(-0.22)\left(\mathrm{m}, 7-\mathrm{H}_{3}\right.$, 11- $\left.\mathrm{H}_{3}\right) \mathrm{ppm}$.

\subsection{Hydrosilylation of PS- $b$-PMSB with VADN}

Exemplary hydrosilylation of PS- $b$-PMSB3 with VADN. In a $50 \mathrm{~mL}$ schlenk-flask equipped with stirring bar toluene (30 mL), PS- $b$-PMSB3 (0.2 g, with $0.90 \mathrm{mmol}$ of Si-H units) and platinum(0)-1,3-divinyl-1,1,3,3-tetramethyldisiloxane complex solution ( $9 \mu \mathrm{L}, 2 \times 10^{-4} \mathrm{~mol} \mathrm{Pt} \mathrm{mol}^{-1}$ of $\mathrm{Si}-\mathrm{H}$ units) are added. After stirring the mixture for $15 \mathrm{~min}$ at room temperature VADN $(0.41 \mathrm{~g}, 0.90 \mathrm{mmol})$ is added and stirring is continued for $120 \mathrm{~h}$ at room temperature. The solution is poured into a 10-fold excess of methanol for precipitation of VADN@PS- $b$ PMSB3 (yield: $0.33 \mathrm{~g}, 31 \%$ ) as yellow solid.

${ }^{1} \mathrm{H}-\mathrm{NMR}\left(\mathrm{CD}_{2} \mathrm{Cl}_{2}, 500 \mathrm{MHz}, 300 \mathrm{~K}\right): \delta=8.21-7.78\left(\mathrm{~m}, 36-\mathrm{H}_{2}\right.$, $\left.39-\mathrm{H}_{2}\right)$, 7.79-6.31 (m, 4- $\mathrm{H}_{2}, 5-\mathrm{H}_{2}, 6-\mathrm{H}_{1}, 18-\mathrm{H}_{1}, 19-\mathrm{H}_{1}, 23-\mathrm{H}_{1}$, $\left.24-\mathrm{H}_{1}, 25-\mathrm{H}_{1}, 25-\mathrm{H}_{1}, 30-\mathrm{H}_{1}, 32-\mathrm{H}_{2}, 33-\mathrm{H}_{2}, 34-\mathrm{H}_{2}, 37-\mathrm{H}_{2}, 38-\mathrm{H}_{2}\right)$, $3.83-3.50$ (m, Si-H, 16- $\mathrm{H}_{2}$ ), 2.64-(-0.70) (m, 1- $\mathrm{H}_{2}, 2-\mathrm{H}_{1}, 7-\mathrm{H}_{3}$, $\left.8-\mathrm{H}_{2}, 9-\mathrm{H}_{2}, 10-\mathrm{H}_{2}, 11-\mathrm{H}_{3}, 12-\mathrm{H}_{2}, 13-\mathrm{H}_{2}, 14-\mathrm{H}_{2}, 15-\mathrm{H}_{2}\right) \mathrm{ppm}$.

\subsection{Block copolymer film preparation}

Block copolymer film samples for investigation of the bulk morphologies are obtained by slowly evaporating methylene chloride solvent from a polymer solution (at room temperature over a period of four weeks). After that time, polymer films are heated to $150{ }^{\circ} \mathrm{C}$ with a heating rate of $50 \mathrm{~K} \mathrm{~min}^{-1}$, keeping the temperature at $150{ }^{\circ} \mathrm{C}$ for $1 \mathrm{~h}$ and again cooled to room temperature with a cooling rate of $50 \mathrm{~K} \mathrm{~min}^{-1}$.

\subsection{Characterization}

NMR spectra were recorded on a Bruker DRX 500 NMR or on a Bruker DRX 300 spectrometer working at $500 \mathrm{MHz}$ or 
$300 \mathrm{MHz}$. NMR chemical shifts are referenced relative to tetramethylsilane. Standard SEC was performed with THF as the mobile phase (flow rate $1 \mathrm{~mL} \mathrm{~min}^{-1}$ ) on a SDV column set from PSS (SDV 1000, SDV 100000 , SDV 1000000 ) at $30{ }^{\circ} \mathrm{C}$. Calibration was carried out using PS standards (from Polymer Standard Service, Mainz). For the SEC-MALLS experiments, a system composed of a Waters 515 pump (Waters, Milford, CT), a TSP AS100 autosampler, a Waters column oven, a Waters 486 UV detector operating at $254 \mathrm{~nm}$, a Waters 410 RI-detector, and a DAWN DSP lightscattering detector (Wyatt Technology, Santa Barbara, CA) was used. For data acquisition and evaluation of the light-scattering experiments, Astra version 4.73 (Wyatt Technology, Santa Barbara, CA) was used. The lightscattering instrument was calibrated using pure toluene, assuming a Rayleigh ratio of $9.7810^{-6} \mathrm{~cm}^{-1}$ at $690 \mathrm{~nm}$. An injection volume of $118 \mu \mathrm{L}$, a sample concentration of 1-2 g $\mathrm{L}^{-1}$, a column temperature of $35^{\circ} \mathrm{C}$, and a THF flow rate of $1 \mathrm{~mL} \mathrm{~min}^{-1}$ have been applied. SEC analysis was performed on a high resolution column set from PSS (SDV $5 \mu \mathrm{m} 10^{6} \AA$, SDV $5 \mu \mathrm{m} 10^{5} \AA$, SDV $5 \mu \mathrm{m} 1000 \AA$ ). TEM experiments were carried out on a Zeiss EM 10 electron microscope operating at $60 \mathrm{kV}$. All shown images were recorded with a slow-scan CCD camera obtained from TRS (Tröndle) in bright field mode. Camera control was computer-aided using the ImageSP software from TRS. CV measurements were carried out on a multipotentiostat VMP2 (Princeton Applied Research) with a custom-made cell in dry methylene chloride with tetrabutylammoniumhexafluorophosphate (TBAHFP) as electrolyte (0.1 M) and ferrocene as standard under nitrogen atmosphere. $\mathrm{Ag} /$ $\mathrm{AgCl}$ reference electrode and $\mathrm{Pt}$ counter electrodes were chosen and a scan rate of $100 \mathrm{mV} \mathrm{s}^{-1}$ in a range of $-0.2 \mathrm{~V}$ to $0.8 \mathrm{~V}$ was applied. TGA was measured using a STA429 (Netzsch Gerätebau GmbH, Selb/Bavaria). The experiments were carried out in TG/DTA mode with an argon flow of $75 \mathrm{~mL} \mathrm{~min}^{-1}$ using a heating rate of $10 \mathrm{~K} \mathrm{~min}^{-1}$. WAXS measurements were conducted using a Stoe Stadi $\mathrm{P}$ with $\mathrm{Ge}_{111}$ as monochromator and a wavelength of $\mathrm{Mo}_{\mathrm{K}, \alpha}=0.7093 \AA$ A . A PSD Klein detector was used. For a qualitative analysis the program Match! from Crystal Impact was used. The corresponding structures were taken from Crystallography Open Database. A quantitative analysis was partially performed by the program Full-Prof using the Rietveld refinement algorithm. Thermal properties of the polymers were characterized using a differential scanning calorimeter (DSC) (Mettler Toledo DSC-1) in the temperature range from $-110^{\circ} \mathrm{C}$ to $180{ }^{\circ} \mathrm{C}$ with a heating rate of $10 \mathrm{~K}$ $\min ^{-1}$.

\section{Results and discussion}

\subsection{Anionic ring-opening polymerization of MSB and sequential polymerization of styrene with MSB}

Liao et al. were the first to report the anionic ring-opening polymerization (ROP) of methylsilacyclobutane (MSB). ${ }^{52}$ Although anionic polymerization using alkyllithium initiator took place, it proved impossible to obtain PMSB homopoly-

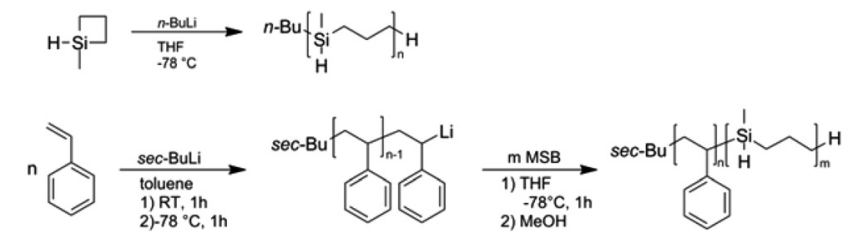

Fig. 2 Anionic ring-opening polymerization of MSB (top) and block copolymerization by sequential monomer addition of styrene and MSB (bottom).

mers with narrow molar mass distributions and polydispersity values $D$ were typically close to $2.0 .^{35,58}$ However, within these studies no detailed information about the character of "livingness" or the kinetic for this anionic ROP was described. Before we turn to the copolymerization of styrene with MSB, we performed experiments to clarify some of these aspects. Polymerization of MSB was carried out as described in the Experimental section and as given in Fig. 2 using $n$-butyllithium as initiator and THF as solvent at $-78{ }^{\circ} \mathrm{C}$.

Results of four different exemplary polymerizations are compiled in Table S1 of the ESI. $\uparrow$ From the obtained yields of the experiments and from results of SEC measurements (Fig. $\mathrm{S} 1 \dagger$ ) it can be concluded that it is challenging to control the anionic ROP of MSB. The molar masses obtained strongly differ from expected values. Remarkably, under these conditions almost quantitative yields of PMSB could be obtained even after 5 minutes of reaction time independent of monomer concentrations or varying reaction temperatures between $-78{ }^{\circ} \mathrm{C}$ and $-90{ }^{\circ} \mathrm{C}$. We additionally performed this reaction in $n$-hexane instead of THF as solvent applying the same reaction protocols. This led to slightly higher molar masses $\left(M_{\mathrm{w}}=41 \mathrm{kDa}\right)$ accompanied with a broadening of the molecular weight distribution $(\nexists=1.84)$. Attempts to subsequently add MSB monomer in order to prove a "living" character of the anionic polymerization also failed as the PMSB chains were not capable of further reaction with MSB monomer. Also the addition of 1,1-diphenylethylene (DPE) immediately after initiator addition to a precooled monomer solution did not result in a typical deep red colour. Hence it can be concluded that it is not possible to control the MSB polymerization by applying herein investigated synthesis protocols due to the remarkably high reactivity of MSB monomer. Nevertheless, it would be feasible to (i) form block copolymers with a structure-directing polymer such as polystyrene (PS) which can be polymerized in a well-defined manner and to (ii) further functionalize PMSB and PS-block-PMSB in a subsequent step by using e.g., hydrosilylation strategies. For this purpose, styrene was polymerized by anionic polymerization and active polymer chains were used as macro-initiator for MSB monomer (Fig. 2). The results are compiled in Table 1 while an exemplary SEC measurement for PS- $b$-PMSB3 is given as Fig. S2. $\uparrow$ It can be concluded that active PS polymer chains were capable of initiating MSB monomer under these conditions (see Experimental section). Due to the excellent control of styrene polymerization, low values for $\triangleq$ could be obtained. 
Table 1 Comparison of molar masses for PS- $b$-PMSB diblock copolymers obtained by sequential anionic polymerization of styrene and subsequent anionic ROP of MSB

\begin{tabular}{llllll}
\hline & $\begin{array}{l}s \text {-BuLi } \\
(\mu \mathrm{mol})\end{array}$ & $\begin{array}{l}M_{\mathrm{w}}{ }^{a} \mathrm{PS} \\
\left(\mathrm{g} \mathrm{mol}^{-1}\right)\end{array}$ & $\begin{array}{l}M_{\mathrm{w}}{ }^{a} \\
(\text { block }) \\
\left(\mathrm{g} \mathrm{mol}^{-1}\right)\end{array}$ & $\begin{array}{l}D \\
(\text { block })\end{array}$ & $\begin{array}{l}\text { Composition } \\
\mathrm{Pt} \%\end{array}$ \\
\hline PS/PMB
\end{tabular}

${ }^{a}$ Molar masses determined by using SEC measurements with PS calibration. ${ }^{b}$ Composition determined by using ${ }^{1} \mathrm{H}$ NMR spectroscopy.

In more detail, values of $D$ for formed PS- $b$-PMSB diblock copolymers were still low and range from 1.03 to 1.08. These results were surprising as homopolymerization could not be performed in a controlled way as discussed above. A possible explanation is that the apparent molar mass of the corresponding block copolymers obtained by using SEC vs. PS calibration is undervalued leading to lower molar masses for PMSB. For comparison, SEC-MALLS measurements of a PMSB featuring an apparent molar mass $\left(M_{\mathrm{w}}\right)$ of $41400 \mathrm{~g} \mathrm{~mol}^{-1} v s$. PS calibration revealed a value of $56300 \mathrm{~g} \mathrm{~mol}^{-1}\left(M_{\mathrm{w}}\right)$ for the absolute molar mass (refractive index increment was determined to be $0.106 \mathrm{~mL} \mathrm{~g}^{-1}$ ). Therefore, values obtained by using SEC vs. PS calibrations for PMSB-containing block copolymers should be treated with caution.

Additionally, ${ }^{1} \mathrm{H}$ NMR spectroscopy measurements revealed that the composition of corresponding diblock copolymers can be adjusted to a maximum content of $42 \%$ per weight for the PMSB block (Table 2). An exemplary ${ }^{1} \mathrm{H}$ NMR spectrum of PS- $b$-PMSB3 is given as Fig. S3 $\uparrow$ while selective areas of stacked ${ }^{1} \mathrm{H}$ NMR spectra showing the aromatic PS region and the $\mathrm{Si}-\mathrm{H}$ signal at $3.77 \mathrm{ppm}$ for all block copolymers is given in Fig. 3 .

In order to investigate the thermal properties of the new PMSB-containing copolymers, DSC measurements were performed for all investigated block copolymers. The glass transition temperatures of PS and PMSB were observable in the expected regions i.e., $100{ }^{\circ} \mathrm{C}$ for $\mathrm{PS}^{68}$ and $-91{ }^{\circ} \mathrm{C}$ for PMSB. ${ }^{35}$ A DSC thermogram of PS- $b$-PMSB3 is given as Fig. S4 in the ESI. $\dagger$ As diblock copolymers consisting of PS as structuredirecting block segment and PMSB with adjustable length

Table 2 Comparison of functionalized PMSB homopolymers by hydrosilylation reaction with NVC, VFc, or VADN by using Karstedt's catalyst

\begin{tabular}{lllllr}
\hline & $\begin{array}{l}M_{\mathrm{n}}{ }^{a} \\
\left(\mathrm{~g} \mathrm{~mol} \mathrm{~mol}^{-1}\right)\end{array}$ & $\begin{array}{l}M_{\mathrm{w}}{ }^{a} \\
\left(\mathrm{~g} \mathrm{~mol}^{-1}\right)\end{array}$ & $D$ & $\begin{array}{l}\mathrm{DS}^{b} \\
(\mathrm{~mol} \%)\end{array}$ & $\begin{array}{r}T_{\mathrm{g}} \\
\left({ }^{\circ} \mathrm{C}\right)\end{array}$ \\
\hline PMSB & 21300 & 34200 & 1.60 & - & -82 \\
NVC@PMSB & 14000 & 39000 & 2.80 & 31 & 22 \\
VFc@PMSB & 19500 & 42000 & 2.16 & 43 & 0 \\
VADN@PMSB & 22100 & 47700 & 2.16 & 26 & 124
\end{tabular}

${ }^{a}$ Molar masses determined by using SEC measurements with PS calibration. ${ }^{b}$ DS: Degree of substitution of $\mathrm{Si}-\mathrm{H}$ moieties for all functional groups (NVC, VFc, VADN) were determined by using ${ }^{1} \mathrm{H}$ NMR spectroscopy.

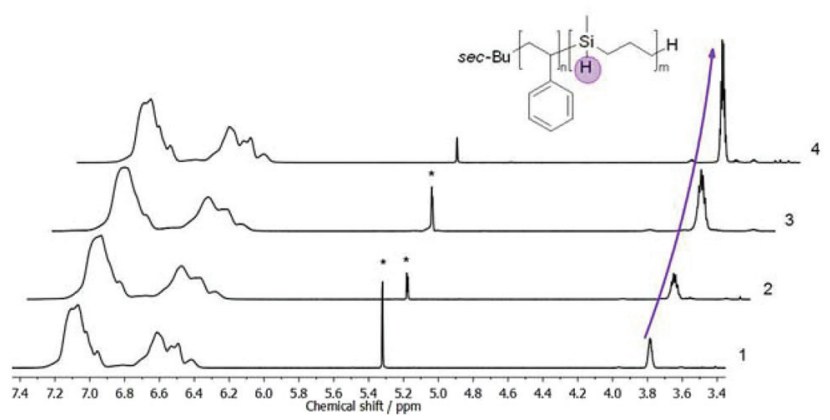

Fig. 3 Stacked ${ }^{1} \mathrm{H}$ NMR spectra of PMSB and all PS- $b$-PMSB diblock copolymers (1-4) as given in Table 1. The increasing amount of PMSB is determined by integration of the $\mathrm{Si}-\mathrm{H}$ signal at $3.77 \mathrm{ppm}$ compared to the aromatic region.

ranging from 17 to $42 \%$ per weight could be obtained, we turn to the investigation of applying hydrosilylation protocols for both PMSB homopolymers as well as the corresponding diblock copolymers with functional monomers in the next section.

\subsection{Hydrosilylation of polycarbosilane homopolymers and block copolymers with pendant functional groups}

Postmodification both of PMSB and PS- $b$-PMSB diblock copolymers was carried out by hydrosilylation using Karstedt's catalyst (Fig. 4). In order to prove the universality of this synthetic approach, functional moieties based on the functional vinyl compounds $N$-vinylcarbazole (NVC), vinylferrocene (VFc), and 9,10-di(1-naphthalenyl)-2-vinylanthracene (VADN) were investigated.

The content of newly introduced functional groups was first determined by using ${ }^{1} \mathrm{H}$ NMR spectroscopy. For calculation of the polymer composition, integration of the aromatic region for the functional moieties NVC, VADN and the cyclopentadienyl-region of ferrocene was compared to the signals stemming from $\mathrm{Si}-\mathrm{CH}_{3}$ signal at $-0.02-0.02 \mathrm{ppm}$ (Fig. S5-7†). SEC measurements of all hydrosilylated PMSB homopolymers featuring NVC, VFc or VADN revealed an increase in molar

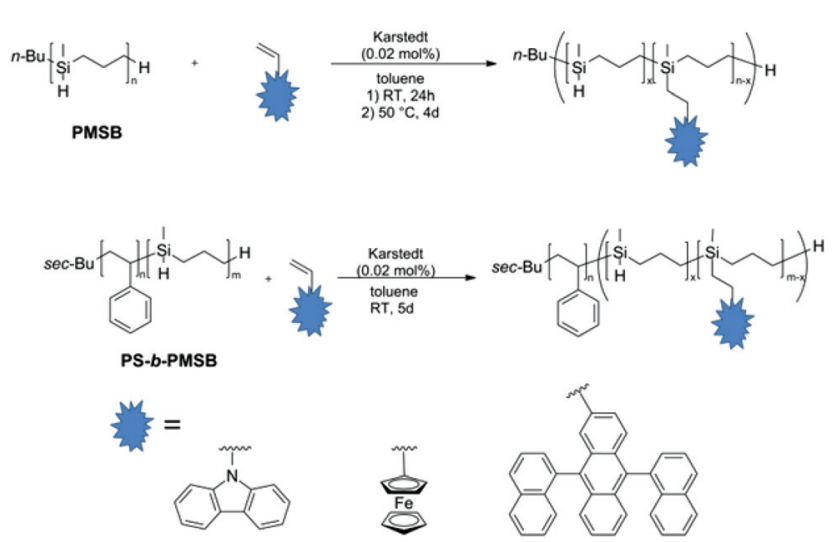

Fig. 4 Hydrosilylation reaction of PMSB with functional vinyl compounds using Karstedt's catalyst (top) and hydrosilylation reaction of diblock copolymers consisting of polystyrene and PMSB (PS-b-PMSB). 
mass for all prepared polymers again proving the feasibility of used postmodification strategy. All results obtained by using SEC and ${ }^{1} \mathrm{H}$ NMR spectroscopy are compiled in Table 2.

DSC measurements of corresponding substituted PMSB polymers revealed an increase in glass transition temperatures, $T_{\mathrm{g}}$, compared to non-functionalized PMSBs. Shifted $T_{\mathrm{g}}$ values are additionally compiled in Table 2 while the corresponding DSC thermograms for NVC@PMSB, VFc@PMSB, and VADN@PMSB are given in the ESI as Fig. S8-S10. $\dagger$ As expected, increase of $T_{\mathrm{g}}$ values nicely fits to the degree of substitution (DS) with sterically demanding moieties which results in a hindered polymer chain segment mobility. It is worthy to mention that the residual $\mathrm{Si}-\mathrm{H}$ moieties after postmodification with investigated bulky vinyl compounds were still capable of undergoing further functionalization with less bulky vinyl compounds. Exemplarily in the case of VFc@PMSB polymers, further hydrosilylation with e.g. styrene could be carried out up to a degree of substitution of $97 \%$ with respect to the $\mathrm{Si}-\mathrm{H}$ moieties. As functionalization of PMSB homopolymers with all three functional monomers could be carried out without problems, we turned to postmodification of PS- $b$-PMSB diblock copolymers again by hydrosilylation in the next step. By applying exactly the same hydrosilylation protocols as for PMSB homopolymers (Fig. 4, middle), various novel functional block copolymers could be obtained. Exemplarily, postmodification of PS- $b$-PMSB having molar masses of $26400 \mathrm{~g} \mathrm{~mol}^{-1}$ (PS- $b$ PMSB1) and $21900 \mathrm{~g} \mathrm{~mol}^{-1}$ (PS- $b$-PMSB3) with NVC, VFc, and VADN was carried out (Fig. 4). Corresponding SEC measurements (Fig. S11-13†) and DSC measurements (stacked Fig. S14 $\dagger$ ) proved the successful postmodification of the polyhydrosilane-segment with functional moieties also for the diblock copolymers. As can be concluded from DSC thermograms, there was no shift of $T_{\mathrm{g}}$ values for the PS segment, while $T_{\mathrm{g}}$ for the PMSB segment shifted according to the degree of substitution with different functional sterically demanding vinyl compounds. Results obtained by SEC, DSC and ${ }^{1} \mathrm{H}$ NMR measurements for the modified block copolymers are compiled in Table 3. Moreover, in order to vary the content of functional groups which are covalently attached to the PMSB backbone, the degree of substitution was modified simply by the addition of certain amounts of vinyl compounds in the hydrosilylation step. Exemplarily, in the case of VFc the content was varied in the range of $28 \mathrm{~mol} \%$ to remarkable $63 \mathrm{~mol} \%$ with respect to the reactive Si-H units.

However, in some cases an additional signal appeared at $3.40 \mathrm{ppm}$ in the corresponding ${ }^{1} \mathrm{H}$ NMR spectra after hydrosilylation reaction of PMSB or corresponding PS- $b$-PMSB using Karstedt's catalyst. Our first assumption was that this signal corresponded to a methyl group of the Markovnikov product (Fig. 5A), which is maybe a by-product during hydrosilylation reaction.

In general, following hydrosilylation strategies, predominantly formation of the anti-Markovnikov product (Fig. 5B) is expected. In order to confirm this first assumption - the formation of a Markovnikov product (A) - we studied NVC@PS- $b$ PMSB1 in more detail via 2D NMR spectroscopy. In detail, in
Table 3 Comparison of functionalized PS- $b$-PMSB1 and PS- $b$-PMSB3 diblock copolymers by hydrosilylation reaction with NVC, VFc or VADN by using Karstedt's catalyst. $T_{\mathrm{g}}$ values for PS- $b$-PMSB1 and PS- $b$-PMSB3 prior to postmodification were determined to be $100{ }^{\circ} \mathrm{C}$ (for PS) and $-91^{\circ} \mathrm{C}$ (for PMSB)

\begin{tabular}{llllll}
\hline Polymer & $\begin{array}{l}M_{\mathrm{n}}{ }^{a} \\
\left(\mathrm{~g} \mathrm{~mol}^{-1}\right)\end{array}$ & $\begin{array}{l}M_{\mathrm{w}}{ }^{a} \\
\left(\mathrm{~g} \mathrm{~mol}^{-1}\right)\end{array}$ & $D$ & $\begin{array}{l}\mathrm{DS}^{b} \\
\left(\mathrm{~mol}^{\circ}\right)\end{array}$ & $\begin{array}{l}T_{\mathrm{g}}(\mathrm{PMSB} / \\
\mathrm{PS})\left({ }^{\circ} \mathrm{C}\right)\end{array}$ \\
\hline NVC@PS-PMSB1 & 35600 & 43200 & 1.21 & 31 & $22 / 98$ \\
NVC@PS-PMSB3 & 27000 & 30500 & 1.13 & 36 & $16 / 99$ \\
VFc@PS-PMSB1 & 27000 & 29300 & 1.08 & 28 & $-23 / 100$ \\
VFc@PS-PMSB3 & 29900 & 39800 & 1.33 & 63 & $6 / 95$ \\
VADN@PS-PMSB1 & 34200 & 37700 & 1.10 & 51 & 109 \\
VADN@PS-PMSB3 & 25600 & 27200 & 1.06 & 48 & 100
\end{tabular}

${ }^{a}$ Molar masses determined by using SEC measurements with PS calibration. ${ }^{b}$ DS: Degree of substitution for all functional groups were determined by using ${ }^{1} \mathrm{H}$ NMR spectroscopy.

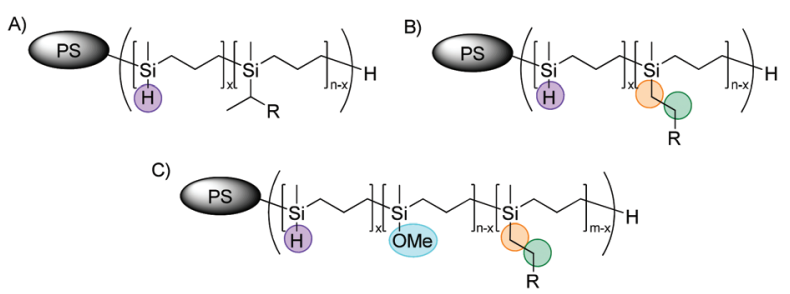

Fig. 5 Possible Markovnikov (A) and expected anti-Markovnikov (B) products formed after hydrosilylation reaction of PS- $b$-PMSB with vinyl compounds and the methoxy-substituted by-product after polymer work-up (C).

order to assign this signal the scalar proton coupling was analyzed through 2D homonuclear correlation measurement (COSY). A section of the aliphatic region of NVC@PS- $b$-PMSB as well as the corresponding ${ }^{1} \mathrm{H}$ NMR spectrum is shown in Fig. 6. For the anti-Markovnikov product the cross-peak appeared due to the spin coupling between the methylene groups. In the case of a Markovnikov product, a correlation between a methyl group and a methine proton would be expected. In fact, however, for the signal at $3.40 \mathrm{ppm}$ no crosspeak was observed leading to the conclusion that possible product A was not formed.

As by-product A could be excluded using 2D NMR techniques, we followed the working hypothesis that the byproduct was formed during polymer work-up protocols after hydrosilylation. Mirza-Aghayan et al. reported the transformation of silanes to corresponding silyl ethers in the presence of transition metal catalysts. ${ }^{69}$ Thus, if the presence of alcohol during the polymer precipitation step can be avoided, no formation of the supposed product C (Fig. 5) will take place. We note that the corresponding ${ }^{1} \mathrm{H}$ NMR signal at $3.40 \mathrm{ppm}$ significantly increases, if the polyhydrocarbosilane is treated with methanol in the presence of Karstedt's catalyst for a prolonged time. This is exemplarily shown for NVC@PS- $b$-PMSB1 which was stirred for $30 \mathrm{~min}$ in the methanol precipitation step. An even more intensive peak appeared at $3.40 \mathrm{ppm}$ of the corresponding ${ }^{1} \mathrm{H}$ NMR spectrum (Fig. S15†). 


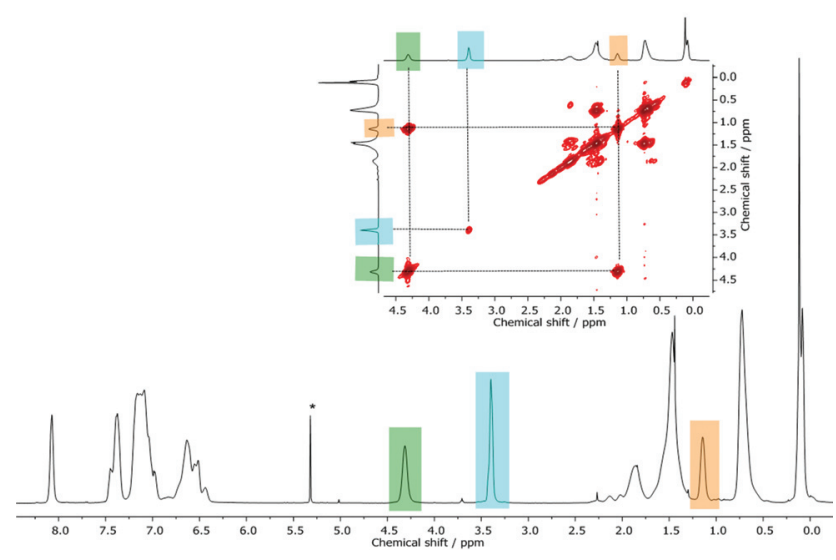

Fig. 6 2D homonuclear correlation measurement (COSY) of NVC@PSb-PMSB1 for exclusion of by-product A shown in Fig. 5 (see text).

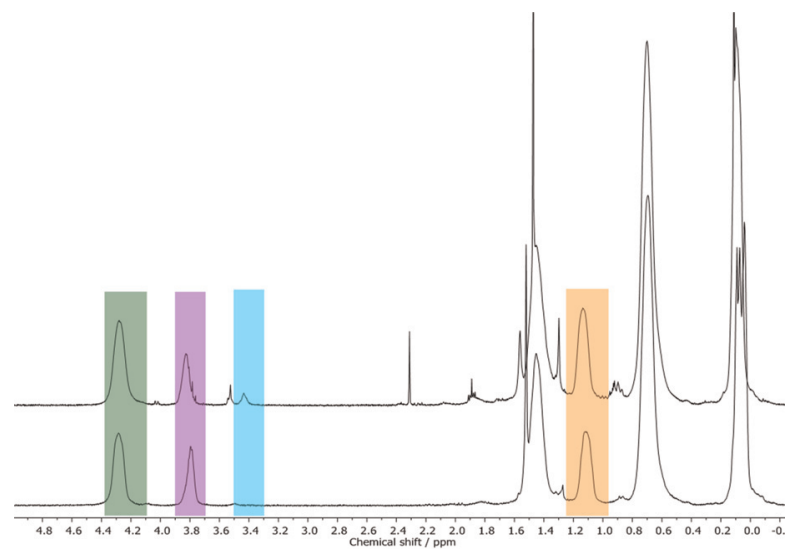

Fig. 7 Stacked ${ }^{1} \mathrm{H}$ NMR spectra of NVC (aPMSB1 precipitated in methanol to form the methoxy-containing by-product $C$ (top) and precipitated in pentane to obtain the anti-Markovnikov product B (bottom).

In order to prove the assumption of silylether formation with methanol, NVC@PMSB1 was precipitated either in methanol or pentane followed by studying the corresponding polymers by using ${ }^{1} \mathrm{H}$ NMR spectroscopy. In Fig. 7, corresponding stacked ${ }^{1} \mathrm{H}$ NMR spectra are given.

It can be concluded from both spectra that pentane is suitable to precipitate (functionalized) hydrosilylated polycarbosilanes without the formation of the methoxy-containing byproduct $\mathrm{C}$ (corresponding signals are highlighted in blue in Fig. 7). As these results comprise the successful formation of functional polyhydrocarbosilane block copolymers featuring different contents of pendant functional groups, first attempts for microphase-separation and potential applications for these novel materials will be provided in the ensuing sections.

\subsection{Microphase-separation of $\mathrm{BC}$ with pendant functional groups}

The block copolymer film preparation is described in detail in the Experimental section. Unfortunately, the pristine PS- $b$ PMSB samples were too soft to prepare thin sections by ultra- microtoming due to the glass transition temperature of $-91{ }^{\circ} \mathrm{C}$ to $-86{ }^{\circ} \mathrm{C}$ for the PMSB segment. However, as the content of $\mathrm{Si}-\mathrm{H}$ group functionalization with sterically demanding NVC, VFc, and VADN monomers increased, also $T_{\mathrm{g}}$ values significantly increased (Table 3). Ultramicrotoming became possible and corresponding thin sections of all samples of Table 3 could be investigated by using TEM. Exemplary images are given in Fig. 8.

All samples were investigated without any staining as functionalized polyhydrocarbosilanes revealed sufficient contrast due to the presence of silicon or iron. Especially ferrocene-containing samples were rich in contrast (Fig. 8C) as it is observed for other ferrocene-containing polymers before. ${ }^{58,66,70,71}$ It can be concluded from all investigated block copolymer samples that a microphase separation with domain sizes in the range of $20-50 \mathrm{~nm}$ were obtained. Due to the fact that no typical nanostructures could be observed the system seems not to be in the equilibrium state. Nevertheless, the domain sizes are of
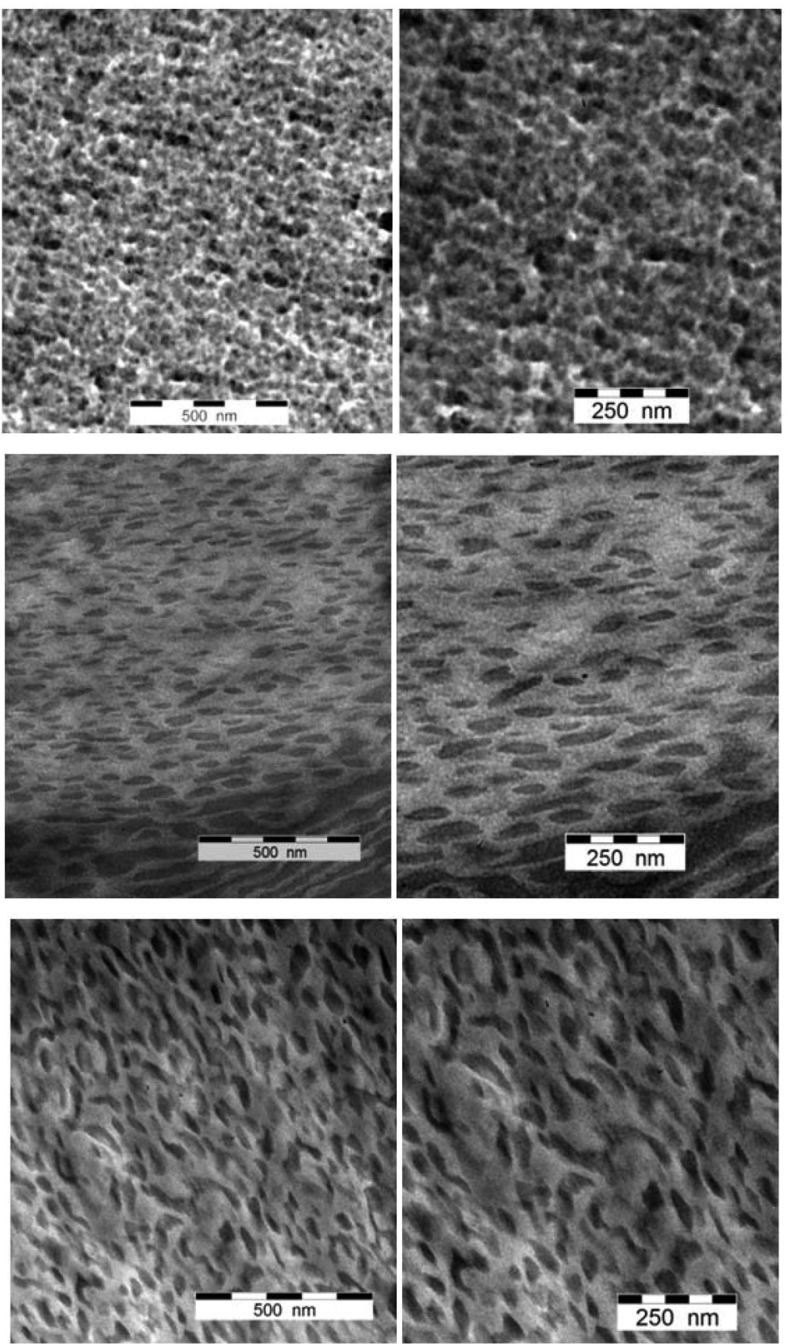

Fig. 8 TEM images of VADNaPS- $b$-PMSB1 (top), NVC@PS- $b$-PMSB1 (middle) and VFcaPS-b-PMSB1 (bottom). Scale bars correspond to $500 \mathrm{~nm}$ (left column) and $250 \mathrm{~nm}$ (right column). 
high interest especially for preceramic block copolymers, e.g. for the preparation of porous structures featuring high surface areas after thermal treatment.

\subsection{Stimuli-responsiveness and ceramization of VFc@PMSB}

In order to prove the potential of these novel functional materials, VFc@PMSB polymers were exemplarily investigated in terms of redox-responsiveness and ceramization.

In general, applications based on ferrocene-containing polymers is an emerging field of recent research comprising e.g., redox-mediated release out of the interior of nanocapsules, ${ }^{19,72}$ for switching the surface wettability and membrane gating, ${ }^{73,74}$ optical applications, ${ }^{75,76}$ or for reversible activity modulation of immobilized catalysts. ${ }^{77}$ All these feasible applications necessitate the chemical or electrical response of the ferrocene moiety. Therefore, cyclic voltammetry (CV) studies for VFc@PMSB were performed (Fig. S16†). As can be concluded from the corresponding cyclic voltammogram, also functionalized ferrocene-containing polymers prepared and investigated within this contribution clearly revealed a redoxresponsive behaviour for at least 24 cycles. The slight shift in the peak potentials is due to the worse solubility of polyvinylferrocenium compared to PVFc in acetonitrile forming a film at the electrodes as described in earlier studies. ${ }^{76}$ We expect our synthetic strategy and easily adjustable protocol for polymer postmodification as excellent model in order to study the influence of the amount of functional groups over a wide range. A deeper understanding of stimuli-responsive polymers is thereof expected which is part of ongoing work.

As already stated in the introduction, metallopolymers and silicon-containing polymers are highly attractive as preceramic polymers. For widening the potential of herein studied functional polymers, VFc@PMSB1 was investigated by using thermogravimetric analysis (TGA). The corresponding diagram of an exemplary TGA of this polymer up to a temperature of $1500{ }^{\circ} \mathrm{C}$ is given as Fig. S17. $\dagger$ Two steps accompanied with a slight weight loss at $210^{\circ} \mathrm{C}$ and a more significant weight loss at $470{ }^{\circ} \mathrm{C}$ could be observed. The final material after ceramization under inert conditions (argon) was analyzed by using XRD. The corresponding XRD pattern (Fig. S18 $\dagger$ ) consists of different series of peaks. As a first result, thermal treatment of VFc@PMSB1 up to a temperature of $1500{ }^{\circ} \mathrm{C}$ under argon enabled the formation of an interesting composite material consisting of $\mathrm{Fe}_{3} \mathrm{Si}, \mathrm{Fe}_{3} \mathrm{Si}_{5}, \mathrm{SiC}$, and graphite. Investigations of properties and potential applications for such type of materials which can be tailored and modified further by using herein established protocols are under way.

\section{Conclusions}

In the current work we present a feasible strategy for the preparation of polyhydrocarbosilane-based block copolymers with polystyrene. Methylsilacyclobutane (MSB) monomer is polymerized by anionic ring-opening polymerization (ROP) followed by postmodification of PMSB homopolymers with three func- tional vinyl compounds i.e., $N$-vinylcarbazole (NVC), vinylferrocene (VFc), and 9,10-di(1-naphthalenyl)-2-vinylanthracene (VADN) by applying hydrosilylation protocols. Degree of substitution (DS) range between $26 \mathrm{~mol} \%$ to $43 \mathrm{~mol} \%$ with respect to the residual $\mathrm{Si}-\mathrm{H}$ moieties of the PMSB polymer backbone. In the case of polystyrene-block-polymethylsilacyclobutane (PS$b$-PMSB) corresponding DS values between $28 \mathrm{~mol} \%$ to $63 \mathrm{~mol}$ $\%$ are obtained. All polymers are investigated by using SEC, NMR, and DSC proving the suitability of herein established synthesis protocols for convenient modification of the PMSB segment. As precipitation of homo- and block copolymers in methanol leads to undesired silylether by-products, polymer work-up procedures are presented in order to obtain welldefined oxygen-free polyhydrocarbosilanes featuring functional moieties. Microphase separation for all functional block copolymer samples are evidenced by TEM measurements after film formation although obtained structures are obviously not in the equilibrium state. Due to the presence of a PMSB segment consisting of polymer chains with significantly broader molecular weight distribution compared to the PS block, worm-like morphologies with domain sizes of approximately $50 \mathrm{~nm}$ are observed. The herein described block-selective hydrosilylation strategy for PMSB and the capability for convenient postmodification with adjustable contents of functional groups are expected to give insight into the mechanism of stimuli-responsive polymers. Moreover, such type of preceramic block copolymers will be advantageously used for the preparation of innovative tailor-made ceramics with adjustable domain sizes.

\section{Acknowledgements}

The authors thank Claudia Fasel (group of Prof. R. Riedel) and Jean-Christoph Jaud (group of Prof. W. Donner) from the Materials Science Department Darmstadt for performing the TGA and XRD measurement, Sabrina Mehlhase, Marion Trautmann, Johannes Elbert, and Daniel Scheid for help with DSC, TEM, and SEC measurements. Jochen Wulff is acknowledged for providing VADN monomer. Additionally, Haiko Didzoleit and Prof. Bernd Stühn (department of physics, TU Darmstadt) are acknowledged for helpful discussions concerning the XRD measurements.

\section{Notes and references}

1 I. W. Hamley, The Physics of Block Copolymers, Oxford University Press, Oxford, 1998.

2 M. Lazzari, G. Liu and S. Lecommandoux, Block Copolymers in Nanoscience, Wiley-VCH, Weinheim, 2006.

3 N. A. Lynd, A. J. Meuler and M. A. Hillmyer, Prog. Polym. Sci., 2008, 33, 875-893.

4 H.-C. Kim, S.-M. Park and W. D. Hinsberg, Chem. Rev., 2010, 110, 146-177. 
5 D. Klinger, M. J. Robb, J. M. Spruell, N. A. Lynd, C. J. Hawker and L. A. Connal, Polym. Chem., 2013, 4, 50385042.

6 R. C. Hayward and D. J. Pochan, Macromolecules, 2010, 43, 3577-3584.

7 F. S. Bates and G. H. Fredrickson, Phys. Today, 1999, 52, 32.

8 M. A. Hillmyer, Adv. Polym. Sci., 2005, 190, 137-181.

9 J. K. Kim, S. Y. Yang, Y. Lee and Y. Kim, Prog. Polym. Sci., 2010, 35, 1325-1349.

10 M. A. C. Stuart, W. T. S. Huck, J. Genzer, M. Müller, C. Ober, M. Stamm, G. B. Sukhorukov, I. Szleifer, V. V. Tsukruk, M. Urban, F. Winnik, S. Zauscher, I. luzinov and S. Minko, Nature, 2010, 9, 101-113.

11 A. E. Smith, X. Xu and C. L. McCormick, Prog. Polym. Sci., 2010, 35, 45-93.

12 D. Han, X. Tong and Y. Zhao, Macromolecules, 2011, 44, 437-439.

13 J. Du, L. Fan and Q. Liu, Macromolecules, 2012, 45, 82758283.

14 J. Hu, H. Meng, G. Li and S. I. Ibekwe, Smart Mater. Struct., 2012, 21, 053001.

15 F. H. Schacher, P. A. Rupar and I. Manners, Angew. Chem., Int. Ed., 2012, 51, 7898-7921.

16 J. I. Clodt, V. Filiz, S. Rangou, K. Buhr, C. Abetz, D. Höche, J. Hahn, A. Jung and V. Abetz, Adv. Funct. Mater., 2013, 23, 731-738.

17 M. Gallei, S. Rangou, V. Filiz, K. Buhr, S. Bolmer, C. Abetz and V. Abetz, Macromol. Chem. Phys., 2013, 214, 1037-1046.

18 B. V. K. J. Schmidt, J. Elbert, C. Barner-Kowollik and M. Gallei, Macromol. Rapid Commun., 2014, 35, 708-714.

19 R. H. Staff, M. Gallei, K. Landfester and D. Crespy, Macromolecules, 2014, 47, 4876-4883.

20 P. R. Malenfant, J. Wan, S. T. Taylor and M. Manoharan, Nat. Nanotechnol., 2007, 2, 43-46.

21 S. Kaur, M. Gallei and E. Ionescu, Adv. Polym. Sci., 2015, 267, 143-185.

22 M. C. Orilall and U. Wiesner, Chem. Soc. Rev., 2011, 40, 520-535.

23 M.-S. She, T.-Y. Lo, H.-Y. Hsueh and R.-M. Ho, NPG Asia Mater., 2013, 5, e42.

24 Y. Ren, Z. Ma and P. G. Bruce, Chem. Soc. Rev., 2012, 41, 4909-4927.

25 P. Innocenzi and L. Malfatti, Chem. Soc. Rev., 2013, 42, 4198-4216.

26 N. D. Petkovich and A. Stein, Chem. Soc. Rev., 2013, 42, 3721-3739.

27 M. Rawolle, M. A. Niedermeier, G. Kaune, J. Perlich, P. Lellig, M. Memesa, Y. J. Cheng, J. S. Gutmann and P. Müller-Buschbaum, Chem. Soc. Rev., 2012, 41, 51315142.

28 I. E. Rauda, R. Buonsanti, L. C. Saldarriaga-Lopez, K. Benjauthrit, L. T. Schelhas, M. Stefik, V. Augustyn, J. Ko, B. Dunn, U. Wiesner, D. J. Milliron and S. H. Tolbert, ACS Nano, 2012, 6, 6386-6399.

29 J. Zhou, G. R. Whittell and I. Manners, Macromolecules, 2014, 47, 3529-3543.
30 A. Gregory and M. H. Stenzel, Prog. Polym. Sci., 2012, 37, 38-105.

31 N. Hadjichristidis, H. Iatrou, M. Pitsikalis and J. Mays, Prog. Polym. Sci., 2006, 31, 1068-1132.

32 S. Ito, R. Goseki, T. Ishizone and A. Hirao, Polym. Chem., 2014, 5, 5523-5534.

33 K. Matyjaszewski, Macromolecules, 2012, 45, 4015-4039.

34 C. Herfurth, D. Voll, J. Buller, J. Weiss, C. Barner-Kowollik and A. Laschewsky, J. Polym. Sci., Part A: Polym. Chem., 2012, 50, 108.

35 C. X. Liao and W. P. Weber, Macromolecules, 1993, 26, 563566.

36 T. Ganicz, W. Staficzyk, E. Biatecka-Florjaficzyk and I. Sledzifiska, Polymer, 1996, 37, 4167-4174.

37 R. Shankar, A. Saxena and A. S. Brar, J. Organomet. Chem., 2001, 628, 262-270.

38 F. Wurm, H. Schüle and H. Frey, Macromolecules, 2008, 41, 9602-9611.

39 F. Wurm, S. Hilf and H. Frey, Chem. - Eur. J., 2009, 15, 9068-9077.

40 H. Kudo, Y. Fujiwara, M. Miyasaka and T. Nishikubo, J. Polym. Sci., Part A: Polym. Chem., 2010, 48, 5746-5751.

41 L. Sacarescu, M. Simionescu, G. Sacarescu and V. Hamciuc, J. Appl. Polym. Sci., 2012, 125, 1284-1291.

42 S. Hilf, P. W. Cyr, D. A. Rider, I. Manners, T. Ishida and Y. Chujo, Macromol. Rapid Commun., 2005, 26, 950-954.

43 I. Martínez-Montero, S. Bruña, A. M. González-Vadillo and I. Cuadrado, Macromolecules, 2014, 47, 1301-1315.

44 G. de la Cruz, H. Schüle, J. Losada, M. P. García-Armada, H. Frey, B. Alonso and C. M. Casado, Eur. J. Inorg. Chem., 2013, 2013, 44-53.

45 P. Boehm, M. Mondeshki and H. Frey, Macromol. Rapid Commun., 2012, 33, 1861-1867.

46 J. Kong, T. Schmalz, G. Motz and A. H. E. Müller, Macromolecules, 2011, 44, 1280-1291.

47 A. G. Marcos, T. M. Puse, R. Thomann, T. Pakula, L. Okrasa, S. Geppert, W. Gronski and H. Frey, Macromolecules, 2006, 39, 971-977.

48 D. Schawaller, B. Clauß and M. R. Buchmeiser, Macromol. Mater. Eng., 2012, 297, 502-522.

49 M. Birot, J.-P. Pillot and J. Dunogues, Chem. Rev., 1995, 95, 1443-1477.

50 R. Riedel, G. Mera, R. Hauser and A. Klonczynski, J. Ceram. Soc. Jpn., 2006, 114, 425-444.

51 S. Q. Zhou, Y. T. Park, G. Manuel and W. P. Weber, Polym. Bull., 1990, 23, 491-496.

52 C. X. Liao and W. P. Weber, Polym. Bull., 1992, 28, 281286.

53 R. Rulkens, A. J. Lough and I. Manners, J. Am. Chem. Soc., 1994, 116, 797-798.

54 M. Suzuki, J. Kotani, S. Gyobu, T. Kaneko and T. Saegusa, Macromolecules, 1994, 27, 2360-2363.

55 V. Bellas and M. Rehahn, Angew. Chem., Int. Ed., 2007, 46, 5082-5104.

56 R. Knischka, H. Frey, U. Rapp and F. J. Mayer-Posner, Macromol. Rapid Commun., 1998, 19, 455-459. 
57 K. Matsumoto and H. Yamaoka, Macromolecules, 1995, 28, 7029-7031.

58 M. Gallei, S. Tockner, R. Klein and M. Rehahn, Macromol. Rapid Commun., 2010, 31, 889-896.

59 M. Gallei, J. Li, J. Elbert, M. Mazurowski, A. Schönberger, C. Schmidt, B. Stühn and M. Rehahn, Polymers, 2013, 5, 284-302.

60 J. Li, B. Kuttich, M. Gallei, J. Elbert, M. Rehahn and B. Stühn, Polymer, 2013, 54, 5703-5711.

61 Q. D. Nghiem and D.-P. Kim, Chem. Mater., 2008, 20, 37353739.

62 K. Matsumoto and H. Matsuoka, J. Polym. Sci., Part A: Polym. Chem., 2005, 43, 3778-3787.

63 I. Natori, Macromolecules, 2006, 39, 6017-6024.

64 N.-G. Kang, Y.-H. Hur, M. Changez, B.-G. Kang, Y.-G. Yu and J.-S. Lee, Polymer, 2013, 54, 5615-5625.

65 H. Mori, H. Ookuma and T. Endo, Macromolecules, 2008, 41, 6925-6934.

66 M. Gallei, R. Klein and M. Rehahn, Macromolecules, 2010, 43, 1844-1854.

67 J. Wang and L. M. Leung, Eur. Polym. J., 2013, 49, 37223733.

68 D. S. Fryer, P. F. Nealey and J. de Pablo, Macromolecules, 2000, 703, 6439-6447.
69 M. Mirza-Aghayan, R. Boukherroub and M. Bolourtchian, J. Organomet. Chem., 2005, 690, 2372-2375.

70 M. Gallei, B. V. K. J. Schmidt, R. Klein and M. Rehahn, Macromol. Rapid Commun., 2009, 30, 1463-1469.

71 R. G. H. Lammertink, M. A. Hempenius, E. L. Thomas and G. J. Vancso, J. Polym. Sci., Part B: Polym. Phys., 1999, 37, 1009-1021.

72 R. H. Staff, M. Gallei, M. Mazurowski, M. Rehahn, R. Berger, K. Landfester and D. Crespy, ACS Nano, 2012, 6, 9042-9049.

73 J. Elbert, M. Gallei, C. Rüttiger, A. Brunsen, H. Didzoleit, B. Stühn and M. Rehahn, Organometallics, 2013, 32, 58735878.

74 J. Elbert, F. Krohm, C. Rüttiger, S. Kienle, H. Didzoleit, B. N. Balzer, T. Hugel, B. Stühn, M. Gallei and A. Brunsen, Adv. Funct. Mater., 2014, 24, 1591-1601.

75 D. Scheid, C. Lederle, S. Vowinkel, C. G. Schäfer, B. Stühn and M. Gallei, J. Mater. Chem. C, 2014, 2, 25832590.

76 D. P. Puzzo, A. C. Arsenault, I. Manners and G. A. Ozin, Angew. Chem., Int. Ed., 2009, 48, 943-947.

77 J. Elbert, J. Mersini, N. Vilbrandt, C. Lederle, M. Kraska, M. Gallei, B. Stühn, H. Plenio and M. Rehahn, Macromolecules, 2013, 46, 4255-4267. 